\title{
Dynamics of Training and Its Vital Role for Organizational Development
}

\author{
Prof. (Meritorious) Dr. Abuzar Wajidi \\ Director, Institute of Health \& Business Management \\ Jinnah Sindh Medical University, Karachi, Pakistan \\ Saima Tabassum \\ Lecturer (Business Administration) \\ University of Sindh, Jamshoro, Pakistan \\ saima.tabassum@usindh.edu.pk
}

\begin{abstract}
:
Purpose: This paper attempts to explore the dynamic nature of training in developing motivation, job satisfaction, organizational change, commitment and retention. This study believes that training process benefits the organization as its multidimensional nature enhances the overall efficiency and effectiveness of work force.

Methodology: The study is based on reevaluating the past research to evolve the impact of training in enhancing efficiency of organization by viewing different perspectives and also discuss its role for effective management.

Findings: The researcher has discussed efficacy of the dynamics of training on organizational development and established in this study that the training is an effective procedure whereby management can easily improve its organizational performance through training based applications mainly employee motivation and job satisfaction among employees. As a result, the training brings positive changes towards organizational development.
\end{abstract}

Research limitations/implications: It has been observed that training also leads some undesirable results at workplace if it has not carried out effectively by the management thus here author should need to highlight the negative consequences of training process.

Practical implications: This study helps in understanding the dynamics of training and its positive impact on behavior of employees by which it can achieve organizational effectiveness.

Originality/value: The paper clearly indicates a certain, significant and dynamic impact of effective training process on job related attitudes of human resources and also emphasizes the vital role of training in achieving organizational goals and prosperity.

Keywords: Dynamics, training, motivation, organizational development.

\section{INTRODUCTION}

It has been agreed upon by many researchers that the training has become very dynamic in its nature. By the time the training has not only got importance due to its impact on the attitude and behavior of employees but also on the overall organizational structure. The training does not limit itself upto the better human productivity but also leaves its upbeat impact on whole organizational culture. It is matter of fact that training has dynamic role to play for bringing real development changes in the organization for its better survivability. The workforce is very important factor in every type of organization but they can be better utilized when they are trained with regard to changing organizational environment and technology.

It is generally agreed that a skilled worker can perform better than a non skilled due to acquiring trainings for familiarization with new emerging techniques. This is the only reason for the Human Resource for their retention with the organization when they are trained and perform efficiently and effectively otherwise they become liability for the employer. Therefore, the training is considered as basic factor for the human development. 
James (1981) said human resource development focuses on the systematic expansion for achieving goals of both organization and employees. To meet the changing needs of time, the organizations require trained Human Resource familiarized with new technologies so that they may compete in the markets to achieve the organizational goals. For this purpose the HR requires regular trainings and development initiatives. Chris Obisi (1996) opined that the objective of training and development is to enhancing absolute power i.e. technical, human and managerial competence for individual and organizational enlargement. The productivity and achievements of every organization are subject to the outcome of its workforce and the performance of that workforce is mainly based on the HRD systems prevailing in that organization. It is a tested theory that better HRD systems win over the better HR performance and resultantly the organization achieves its goals. Benedict and Fabia, (2010) that there is a big difference between organizations that train their employees and the organizations that do not. The training has proved its importance when organizations with trained HR and untrained HR compete with each other in the markets. The training creates professionalism which infact attracts the clients with quality productions, customer needs and business market philosophy. Evans and Lindsay (1999), Organizations which are dedicated to generating profits for their owners (shareholders) and provide high quality services to their clients and beneficiaries usually invest in training their employees. It has been surveyed globally by the business management researchers that mostly the profit oriented organizations invest for the trainings to get their work force trained to compete in the world business markets. Even, the service / welfare oriented organizations (non profitable organizations) also invest for the trainings to get their HR trained for getting better human productivity from their existing resources.

\section{Training}

Transfer of knowledge and skills is done through a process which is called training. The training improves the human productivity and resultantly it makes the difference between performance of trained and untrained Human Resource.

Flippo (1984), training is the act of increasing knowledge \& skills of an employee to perform a specific task. According to Steinmetz (1968), training is an organized procedure whereby an individual learns technical / professional knowledge and skills for performing particular tasks. Here one can understand the importance of training that it is the well tested process/ tool of learning in systematic way whereby individuals learn new techniques essentially required for doing their jobs in better way.

The management researchers Oguntimehin (2001), Akintayo (1996), and Graig (1976) Akinpeju (1999) highlighted the importance of training, and accredited the functions of training as enlarge efficiency, enhance the quality of work, ameliorate skills, knowledge and attitude; increase the usage of machine and tools, job satisfaction; trim down desecrate, accidents, turnover, absenteeism and other operating cost; remove intricacy in skills, technologies, procedures and resources management. One of them (Akinpeju) was of the opinion that training and development is never-ending process for meeting individual job performances efficiently and achieving organizational goal effectively. The training not only provides the organizations a variety of better management systems to run their affairs but also bring many new techniques for the positive change in attitude and aptitude of their human resource for achieving organizational goals. It has been endorsed by the many researchers that the training and development works for better management policies, procedures, transfer of research based knowledge and skills, technological systems to meet existing work requirements of the individuals and organizations which ultimately which factors improve the work performance and training bridges the gap between current skills of individuals and the standard desired performance.

\section{Training Methods}

There are certain types / methods of training likewise coaching and mentoring, colleagues interaction and participation by employees. In most of the organizations it has been observed that the team work provides the employees the best chance to learning exchange on the job which also leaves good affects on the overall organizational goals and achievements.

Jie and Roger, (2005) said that trainings polish the individuals/workers with regard to their attitude and aptitude and which in due course help organizations to make best use of their human resources. It is therefore thought necessary by organizations to plan trainings for their employees to polish and enhance their abilities and competence required for the job performance. David, (2006) said that the 
training develops the ability of the employees and sharpens their thinking ability and enhances creativity in order to make a better decision in time and in a more productive manner. Hollenbeck, Derure and Guzzo's (2004) description of the training is that it teaches how to deal effectively with customers and employees to respond to complaints in a professionally sound manner. Kathiravan, Devadason and Zakkeer (2006) Svenja (2007) said that work more effectively and efficiently than traditional poor behavior, performance, the learning experience to change the results of self-efficacy and development. Chiaburu and Tekleab, (2005) Training refers to a planned intervention aimed at enhancing the elements of individual job performance". Chen et al., (2004) training seems to be necessary to achieve the goals of organization. Training works reducing anxiety or frustration among employees, and resultantly helps to reduce the employee turnout. To fill up the gap between the skills and manpower, the training is thought necessary by the organizations for reduction in employee job dissatisfaction. Rowden, Conine (2005) and Tsai ET al., (2007), a result of the training, employees become more effective and productive.

\section{DYNAMics OF Training}

Training is an important tool for the organizational development. A trained employee will become more efficient and productive than an untrained. It has been endorsed by many researchers that training is dynamic in its nature and by the time training is going to become need of time and this is the reasons that organizations considering its importance invest on trainings of their employees so that their efficiency may be improved and the organizations may get their goals through their trained employees as the trained employees perform better than untrained. Organizations are agreed that due to trainings of employees their losses go down due to efficient and effective performance / working of their employees. The dynamics of training also emphasized on the employee's efficiency, job satisfaction, motivation, innovation, organizational commitment and abridged turnover. It is agreed principle that training shapes the person and also reduces lacuna in his professional life.

\section{Training AND Motivation}

The motivation is the basics of training. It encourages the individuals and organizations emotions to perform better to achieve their goals well in time. In the organizations, the motivation is done when appreciation of work is given by the employer to its employees during the job. Training and motivation are inter dependent on each other that is why both go parallel and form a better human resource product. Through training process the individuals are motivated not only to learn the new ideas, knowledge, skills and techniques about their job for proving themselves worthy of a job but also to improve their overall attitude / behavior towards their management, coworkers, subordinates, customers and competitors as well. The motivation has correlation with the inner feelings of individual and shapes the individual's behaviors towards various activities by him. It is also said that the training emphasizes initially on human behavior to set individual's inclination towards the required job performance which can only be improved only by motivation tool. When the organizations provide congenial working environment to their employees, assures for their safety and security and address their problems at work and fulfill their basic needs and morally encourage them they perform better and as such organizational goals are achieved. Many business entities invest for new training methods likewise motivation based learning programmes. Many surveys have been conducted by researchers for knowing the factual impact of motivation based trainings on organization and individual performance and such surveys have ascertained that motivation based trainings have long-term impact on performance of organization and individual. Sylvie and Sire, (2001), said that training and motivation are correlated with post training satisfaction. Bodimer (2009), employee motivation factor is result of effective training program. It is also very important for the organization that when they conduct training program they must taken into consideration the value adding training content and material which may properly cover the training need assessment. According to researchers Sylvie and Sire (2001) the every human have different set of skills and talents and it is responsibility of organization to manage the expertise / competencies of their employees keeping them motivated through effective trainings to sharpen their skills for the betterment and success of organization. But in case the motivation of employees is not done properly then organizational systems may get weaker and suffer. 


\section{Training AND Job SATISFACTION}

The research studies have established that the job satisfaction leaves through impact on individual's performance. It has been defined by chermerhorn. Junior, ET al., (2005), job satisfaction is a factor which determines positivity and negativity of an individual about his job.

It has been found through many surveys that it becomes difficult for an individual when he is not satisfied with his job and may perform better therefore the globally recognized business organizations feel it necessary to conduct trainings on the job satisfaction factors. It is understood that when individual is satisfied with his current job he can even go for improvement in his current performance. As there are many factors which badly affect the job satisfaction i.e lack of proper heed towards employees' motivation / appreciation on his better work performance, equality of employee rights, health care, salary incentives, employee safety \& security, job protection, merit based career growth and provision of congenial working environment and other fringe benefits. The job satisfaction is related to professional life of individual and for a human the professional life is as important as his personal life. It is therefore said that when one is satisfied with his job he can even motivate coworkers and subordinates and may do maximum to get recognition by the employer. As for as the impact of training on job satisfaction is concerned the many studies have ascertained that training improves the job satisfaction level of an individual.

\section{Training and Organizational Change}

No one organization can deny the importance of role of the training in the organizational change towards the organizational development / productivity. It is also an established theory by a management researcher Coulter (2005) that the organizational change is that any alteration in the Performance of human resource, arrangements, systems or technology. It has been found that the sustainable development and desired performance standards are achieved by using training methodology, up to date knowledge and most modern machinery with qualified human resource.

Organizational changes are of two types; one is reactive and other one is proactive. The reactive is that change which takes place for revising the organizational structure/systems, technology / machinery, human resource for solving the sudden problems. The reactive changes are preferred by the organizations in comparison of proactive change applications.

The proactive change is considered well before the occurrence of performance gap / expected occurrence of problems as such organizations go for proactive change applications to put in order themselves for avoiding occurrence of certain problems in future. Most of the organizations have observed that the proactive change approach is better than the reactive approach for the sustainable development of organization and also the proactive change approach may be more economical than the reactive change approach. Here a question that why organizational change is required? In answer, it is said that there are some certain external and internal forces which create the need for organizational change. The external factors are including mostly the business competition in market places, enforcement of government laws, rules, regulation and policies, latest technology, labor markets, national / international economic issues etc. The Internal factors include the labour issues, changing technology, employee attitudes, diversified workforce, strategic plans, financial issues, productivity issues. According to Snyder and Cummings (1998) that the capabilities of organizations for change are essential for its endurance. This ability to change is allied with organizational learning. Organizations learn from their past experience. According to Schein (1999) that if management of any organization does not pay proper heed to the problems and necessary organizational needs requiring proactive or reactive change in the structure, technology or employees attitude, it may generate anxiety and cause fall down of organization. A lady researcher Ms. Antonacopoulou (2001) hypothesized that there are significant interrelationships among training, learning and change. She identified that paradoxically managers believe that training was a abates to learning in that the formation, timing and matching with learners needs, but managers have to accept that learning is ongoing and essence of training and she further specified that the structured training is constantly not a learning break.

\section{Training AND TURNOVER}

Many research studies have proved that the training reduces the turnover rate in organization. It is said that the employee turnover means the employee leaving ratio of an organization. To know the impact 
of training on employee turnover, it is very necessary to find out that why an individual quits / gives up his/her job. According to Leininger (2004), there are number of distinctive characteristics that include higher pay and finding a better career prospect make employees to leave their job. Besides, the reasons of leaving organization may be of different types but mostly these include lack of training, incapability of employee to perform job, career advancement, lack of merit based performance appraisal, frustration due to deprivation of employee legitimate rights, uncongenial working environment, lack of motivation / appreciation, lack of incentive / fringe benefits, favoritism, nepotism, lack of employee-management relationship. Therefore, the training option only remains there for solving many such problems because training bridges the gap between the need and its realization/fulfillment. Here are some examples: an untrained employee is like a dull school student who prefers to remain absent and likely to be a school drop-out unlike other students who are good at studies and enjoy schooling. An incapable / unproductive worker is frustrated by failure and is likely to dump his work than those who are capable of producing / productive.

Chughtai and Zafar (2006) carried out survey on the impact of the organization's commitment to the dimensions of organizational results. It included employee performance, business plans and job satisfaction, pay, promotion, supervisors's attitude, work safety, and training opportunities The researchers collected data from 125 university teachers (male \& female). Data was analyzed on multiregression basis to test the application to the relationship. It was found that training opportunities are positively correlated with organizational commitment. It was also seen that lowest variation of satisfaction showed significant effect on organizational commitment, and training opportunities. Further observed that efficiency and commitment were related to business intention; and said that employees have to be better performers with the level of commitment and love to work on their respective working places that concluded.

\section{Training and Organizational Commitment}

Mowday, Spears and (1979), Porter show commitment to its employees' involvement in the organization and determine the relative strength of the individual. "Organizational commitment is that not to leave the organization and further sais that the organization and the employee has a psychological connection. (Allen \& Meyer, 1996), the organizational commitment is regarded as profits and investments by getting done the individual activities.

Meyer and Allen (1991), emphasized on more commitment, and three different mechanisms: (i) affective commitment (ii) normative commitment (iii) continued commitment. Kantor (1968), divided organizational commitment into three sections (i) continuance dedication (ii) commitment (iii) consistency control participation. The researchers feel that the responsibility of retention of an employee in the organization depends on organizational commitment. However, the continuation of employees, leaving organization results into employees "went costs".

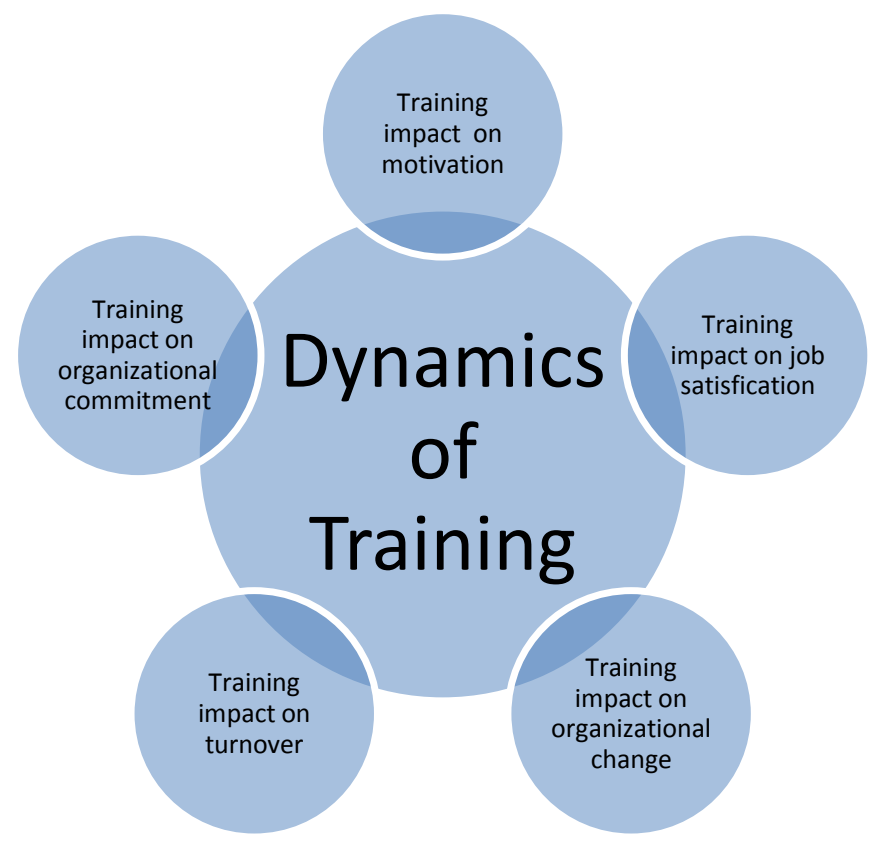


Rylander (2003) argues that research to discover the change in the organization Commitment and the satisfaction of training and the Equity Commitment of team of the sales force. A research was carried out through a data sample of 535 new trainees. Wherein it was shown that training leaves better impact on organizational Commitment. The research also shared that enhanced training dissatisfaction, lack of commitment and perception of reward in the demarcation Organization increase engagement of the equity in nursery.

\section{CONCLUSION}

From the perusal of this study it is concluded that that dynamics of trainings leaves better impact on employee motivation, job satisfaction, organizational change, turn over and organizational commitment. Therefore, training is an important factor for the organizational development and is an essential tool for all employees working for achieving organization's success/goals. It is useful for both employees and employers. If employees are trained then they will be more effective and useful for the organizations as the training improves the quality of work. Training is a need not only for better performance, but it also motivates and encourages employees towards organizational commitment. Training provides all the information necessary to perform the operation to increase productivity.

The success or failure of the organization depends on employee performance. Omole (1983) saw that the management are interested in the training of their employees, because with the acquisition of skills required of workers would go a long way to improve performance. He added that if the workers do not know certain things, the performance of which they intend to improve, perhaps even decrease due to lack of technical expertise. During training a person learns to trust his ability to perform better and believes that he can have a better control over organizational work and environment and is equipped to cope up with occasional disappointment, frustration and inconvenience. He also learns to streamline and take the blame for its own failures instead of blaming the organization. Employee Training receives the inner satisfaction from their work, which contributes to morale. Organizations that have regular training programs give employees a sense of purpose and something to look up to.

Training helps to coordinate people and materials. During the training program, the expectations and objectives of an organization are emphasized and they are showed a ladder through they can achieve their organizational goals, and therefore, it leads to a comparison target. In general, training helps to reduce staff turnover and enhances achievement of organizational goals, while the lack of training increases the rate of absenteeism, low productivity, low quality and results in a high unit cost.

\section{REFERENCES}

Anonymous. (1998, Sept/Oct). What nonprofits need to know about technology. Nonprofit World, 16, 38

Benedicta Appiah April, (2010), "The impact of training on employee performance: A Case Study of HFC Bank (GHANA) Ltd”. Pp. 15-17

Evans, J. R. and Lindsay W. M., (1999), "The Management and Control of Quality", 4th edition, South-Westernllege College Publishing, Cincinnati Ohio, USA

Robbins, S. P. and Coulter mary (2005). Management. (08th Edition), Upper Saddle River, New Jersey: Prentice Hall, P.312.

Chirs Obisi (1996) "Personal Management” Jackbod Enterprises.Ojokondo Layout Agbowo,Ibadan.

Snyder, W.and Cummungs, Th.(1998), "Organization learning disorders: conceptual model and intervention hypothesegfgjhjhhos",Human relations, Vol.51 No7, pp.873-95.

Forss, K.,Cracknell, B.and Samset, K.(1994) "Can evaluation help an organization to learn?" Evaluation Review, Vol.18 No.5, pp.574-91.

Schein,E.H.(1999), "Kurt Lewin's change theory in the field and in the classroom: notes towards a model of managed learning", Reflections, Vol. 01 No. 01,pp.59-74.

Antonacopoulou, E.P (2001), "The paradoxical nature of relationship between training and learning", Journal of Management Studies, Vol.38 No.3, pp.327-50.

Butkus, R.T. \& Green, T.B. 1999. Motivation, Beliefs and organizational Transformation Organizational Quorum Books.

Baron, R.A. (1983). Behaviour in organizations. New York: Allyn \& Bacon, Inc. 
Kreitner, R., \& Kinicki, A. (2001). Organizational Behaviour (5thed.). McGraw-Hill companies, Inc, P.205-208.

Leininger ,J.(2004).The Key to Retention: Committed employees China Business Review,31(10,16$17,38-39 \mathrm{Ja} / \mathrm{F}$.

Chughtai.A.A.\& Zafar.S.(2006). Antecedents \& Consequences of Organizational commitment among Pakistani university teachers. Applied H.R.M.Research,11,1,39-64

Allen, N.J.and Meyer, J.P. (1996), 'Affective, Continuance and Normative Commitment to the Organization: an Examination of Construct Validity,' Journal of vocational behavior, 49,252-76.

Allen, N.J.and Meyer, J.P.(1990), 'The Measurement And Antecedents Of Affective, Continuance And Normative Commitment To The Organization, 'Journal of Occupational Psychology,63,118.

Kantor, R.M. (1968) "Commitment and social organization : a study of commitment Mechanisms in utopian communities:. American Sociological Review, 33:499-517.

Mowday ,R.T.,Porter, L.W.and Steers ,R.M.(1982), Employee -Organizational Linkages : the psychology of Commitment, Absenteeism, and Turnover (New York: Academic)

Peter J. McGunnigle, Stephanie M. Jameson, (2000) "HRM in UK hotels: a focus on commitment", Employee Relations, Vol. 22 Iss: 4, pp.403-422

Meyer, J.P. and Allen, N.J.(1997) . Commitment in the work place: theory .research and application, Thousand Oak, CA: Sage.

Meyer ,J.P. \& Allen ,N.J.(1990). Commitment in the workplace. Thousand Oaks, CA:Sage Publications.

Rylander.David.H.(2003).Changes in Organizational commitment for Sales force newcomers : An Exploratory look at early employment influences. Small Business Institute Journal, October 2004 .www.saber.uca.edu/resssaerch/acme/2003/papers/new/24.pdf.

Becker, H.S. (1960) .notes on the concept of commitment .American Journal of Sociology, 66,32-40

\section{Authors' BIOGRAPHY}

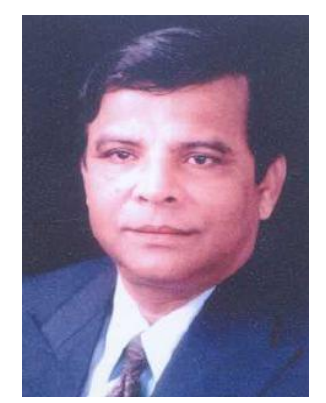

Prof. (Meritorious) Dr. Abuzar Wajidi, Ph.D in Management Sciences.

Current Position: Director, Institute of Health \& Business Management Jinnah Sindh Medical University, Karachi, Pakistan.

Important position(s) held: Served as Acting Vice Chancellor, University of Karachi, Pakistan.

Served as Dean, Faculty of Management Sciences, University of Karachi, Pakistan.

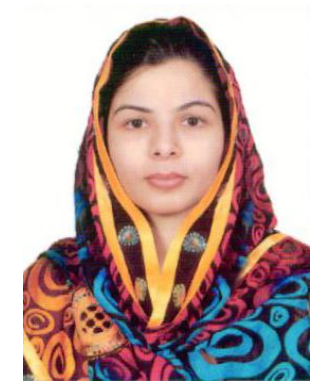

Saima Tabassum (Mrs.), Ph.D in Management Science from University of Karachi (ongoing), Karachi, Pakistan. M.S from Hamdard University, Karachi, Pakistan. MBA (Honors) from IBA, University of Sindh, Jamshoro, Pakistan. BBA from IBA, University of Sindh, Jamshoro, Pakistan.

Service: Lecturer (Business Administration), University of Sindh, Jamshoro, Pakistan since 15-01-2007. 